EESTI NSV TEADUSTE AKADEEMIA TOIMETISED. XVI KOIDE KEEMIA * GEOLOOGIA. 1967, NR. 1

ИЗВЕСТИЯ АКАДЕМИН НАУК ЭСТОНСКОН ССР. ТОМ XVI ХИМИЯ - ГЕОЛОГИя. 1967, 스 4

К. ЛЭЭТС, С. ТЕНГ

\title{
О МЕТОДАХ ВЫДЕЛЕНИЯ И ПОЛУЧЕНИЯ ГЕРАНИОЛА И НЕРОЛА
}

Выделение из прнродных эфнрных масел индивндуальных цис- и транс-изомеров важнейшнх представителей алнфатическнх монотерпеновых спнртов - нерола и гераниола, а также их полученне сннтетическнм путем представляет несомненный теоретическнй н практический ннтерес. Этому вопросу посвящено множество исследованнй, опублнкованных в орнгинальной н патентной литературе. В большинстве опубликованных работ полученные продукты недостаточно охарактеризованы с точки зрения нзомерного состава. Поэтому мы сочлн целесообразным провести проверку опубликованных способов при помощи современных фнзико-химических методов анализа, Решенне поставленной задачн значнтельно облегчалось благодаря нспользованию высокоэффежтивных методов газовой хроматографни терпеновых окснпроизводных, разработанных в нашей лаборатории [1].

В работе исследовались различные методы получения индивндуальных образцов гераниола и нерола из соответствующих техническнх спиртов, а также из цитраля, полученного при окислении линалоола, выделенного из кориандрового масла. Для определения индивидуального состава исходных продуктов и продуктов их переработки использовались газовая хроматография, а также метод преврашения выделенных спиртов в соответствующие хлорпронзводные при помощи $\mathrm{PCl}_{5}\left[{ }^{2}\right]$ с последующим определением в получаемых продуктах содержания первичных хлоридов аллильного типа [3] и превращения их в альдегиды по реакции Соммле (см. $\left.\left[{ }^{4}\right]\right)$. Указанные методы позволнли сделать убедительные выводы о препаративной пригодности того или иного способа получения вышеуказанных изомерных спиртов достаточной чистоты.

Для выделения гераниола из продуктов природного происхождения обычно используется, кроме обычной ректификации, способ выделения его через соединение с хлористым кальцием [5]. Нами было установлено, что из технических смесей, содержащих около $40 \%$ гераниола, последний может быть выделен при помощи хлористого кальция с хорошнм выходом и достаточной чистотой. Из исследованных технических образцов выделить чистый гераниол удалось при помощи точной вакуумной ректификации на насадочной колонке из стекла «Пирекс» при давлении 5 мм и температуре в кубе, не превышающей $150^{\circ} \mathrm{C}$.

Выделение нерола из продуктов природного происхождения затрудняется его малым содержанием в них. Препаративный интерес представляют опубликованные способы получения нерола при изомеризации гераниола под влиянием щелочей, алкоголятов металлов [6], треххлористого бора $\left[{ }^{7,8}\right]$ или йодистоводородной кислоты $\left[{ }^{9}\right]$, при изомернзации линалоола путем его этерификации $\left[{ }^{10}\right]$, а также восстановление 
цитраля при помоши алкоголятов алюминия по методу, описанному в работе ["]. Более подробному исследованию подвергались нами методы, изложенные в $[6,9,11]$.

Таблица 1

Изомеризация гераниола

\begin{tabular}{|c|c|c|c|c|c|c|c|c|c|c|c|c|c|c|c|c|}
\hline \multirow{2}{*}{$\begin{array}{l}\frac{\pi}{3} \\
\text { 恶 } \\
2 \\
2 .\end{array}$} & \multirow[b]{2}{*}{ Катализатор } & \multicolumn{2}{|c|}{$\begin{array}{c}\text { Состав } \\
\text { реакцнон- } \\
\text { ной смесн, } \\
2\end{array}$} & \multirow[b]{2}{*}{ 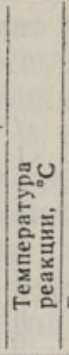 } & \multirow[b]{2}{*}{ 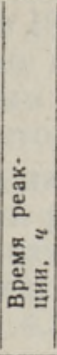 } & \multicolumn{2}{|c|}{$\begin{array}{c}\text { Выход } \\
\text { продукта }\end{array}$} & \multirow[b]{2}{*}{ 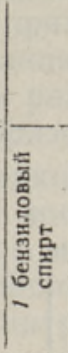 } & \multicolumn{6}{|c|}{$\begin{array}{l}\text { Номер (по рнс. 1) и } \\
\text { состав нродукта, \% }\end{array}$} & & \multirow{2}{*}{ 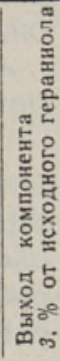 } \\
\hline & & 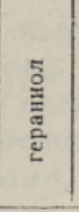 & 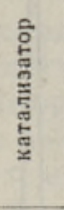 & & & $\psi$ & 2 & & 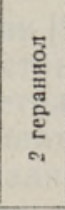 & $\infty$ & $*$ & 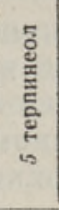 & 6 & 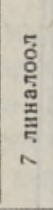 & 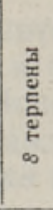 & \\
\hline 1 & $\begin{array}{l}\text { Бензилат } \\
\text { алюмниия }\end{array}$ & 14,5 & 2,9 & 230 & 1 & 4,2 & 29,0 & - & 8,2 & 51,7 & 7,6 & 20,7 & 2,0 & 2,9 & 6,9 & 10,5 \\
\hline 2 & То же & 20,0 & 4,0 & 230 & 1 & 15,4 & 77,0 & 13,6 & 9,2 & 43,9 & 13,5 & 13,2 & 2,0 & 0,6 & 4,0 & 33,8 \\
\hline 3 & " & 10,0 & 2,0 & 230 & 1 & 8,2 & 82,0 & 16,6 & 13,0 & 45,6 & 10,7 & 9,8 & 1,2 & 0,3 & 2,8 & 37,4 \\
\hline 4 & " & 10,0 & 2,0 & 160 & 4 & 6,4 & 64,0 & 9,7 & 42,3 & 33,2 & 11,0 & 3,4 & - & 0,4 & - & 21,1 \\
\hline 5 & , $\quad$. & 10,0 & 2,0 & 160 & 4 & 9,2 & 92,0 & 17,6 & 51,0 & 15,8 & 9,0 & 6,3 & - & 0,3 & - & 46,9 \\
\hline 6 & $\mathrm{NaOH}$ & 10,0 & 0,5 & $\begin{array}{c}120 \\
(10) M\end{array}$ & 1 & 7,0 & 70,0 & - & 42,7 & 35,8 & - & 20,6 & - & 0,9 & - & 25,1 \\
\hline 7 & .. & 18,4 & 2,3 & 80 & 3 & 12,4 & 67,4 & - & 100,0 & - & - & - & - & - & - & - \\
\hline 8 & KOH & 10,0 & 1,0 & 130 & 3 & 3,6 & 36,0 & 一 & 43,0 & 13,2 & 2,4 & 40,0 & $\rightarrow$ & 1.8 & - & 4,8 \\
\hline 9 & $\begin{array}{c}\text { Бензилат } \\
\text { натрия }\end{array}$ & 10,0 & $2,0^{\prime}$ & $\begin{array}{c}(20 \mathrm{M}, \mathrm{M} \\
160\end{array}$ & "u) 2 & 4,7 & 47,0 & - & 26,6 & 30,5 & - & 22,8 & - & 20,1 & - & 14,3 \\
\hline 10 & $\begin{array}{r}\text { Бензилат } \\
\text { магния }\end{array}$ & 10,0 & 2,0 & 160 & 3 & 6,5 & 65,0 & - & 89,3 & 8.7 & - & 1,2 & - & 0,8 & - & 8,7 \\
\hline 11 & $\begin{array}{c}\text { Нзопропнлат } \\
\text { алюминия }\end{array}$ & 10,2 & 0,5 & $\begin{array}{c}130 \\
(5 \cdot M)\end{array}$ & ) & 7,8 & 76,5 & - & 100,0 & - & - & - & - & - & - & - \\
\hline
\end{tabular}

По данным, прнведенным в патенте [6], гераниол под каталитическим влиянием алкоголятов металлов или гидроокисей последних при повышенных температурах превращается в нерол с выходом 45-50\%. Кроме того, регенерируется $30 \%$ гераниола.

Данные патента были подвергнуты проверке с использованием выделенного нами чистого гераниола (табл. 1 , опыты $1,4,6,7$ ). С целью голучения дополнительного материала о данной реакции были проведены опыты с другими катализаторами аналогичного характера (табл. 1, опыты 8-11). По результатам проведенных исследований можно заключить, что гераниол изомеризуется не в нерол с выходом 45-50\%, а в сложную смесь терпенов и спиртов (табл. 1 ; рис. 1 ). Выход изомеризата зависит от катализатора и способа выделения продукта из реакционной смеси, его качественный состав мало изменяется в отдельных случаях. Катализаторы $\mathrm{NaOH}$ и $\mathrm{KOH}$, кроме изомеризации, вызывают и полимеризацию гераниола (табл. 1, опыты 6,8 ), выход изомеризованных спиртов значительно ниже, чем в случае бензилата алюминия (табл. 1, опыт 5). Малое изомеризующее действие имеют бензилаты магния и натрия (табл. 1, опыты 9, 10), изомеризацию не вызывают $\mathrm{NaOH}$ в бензоле и изопропилат алюминия (табл. 1, опыты 7 , 11). При нспользовании перегонки под уменьшенным давлением продолжительность процесса выделения изомеризата уменьшается, выход изомеризата (табл. 1, опыты $2,3,5)$ увеличивается по сравнению с перегонкой с водяным паром (табл. 1 , опыты 1,4 ). Для изучения и идентификации состава изомеризата применяли вакуумную ректификацию и 
газовую хроматографию. При помощи эталонных веществ установили, что пики на хроматограмме (рис. 1) соответствуют следующим вещестьам: 1 - бензиловый спирт, 2 - гераниол, 5 - терпинеол, 7 - линалоол.

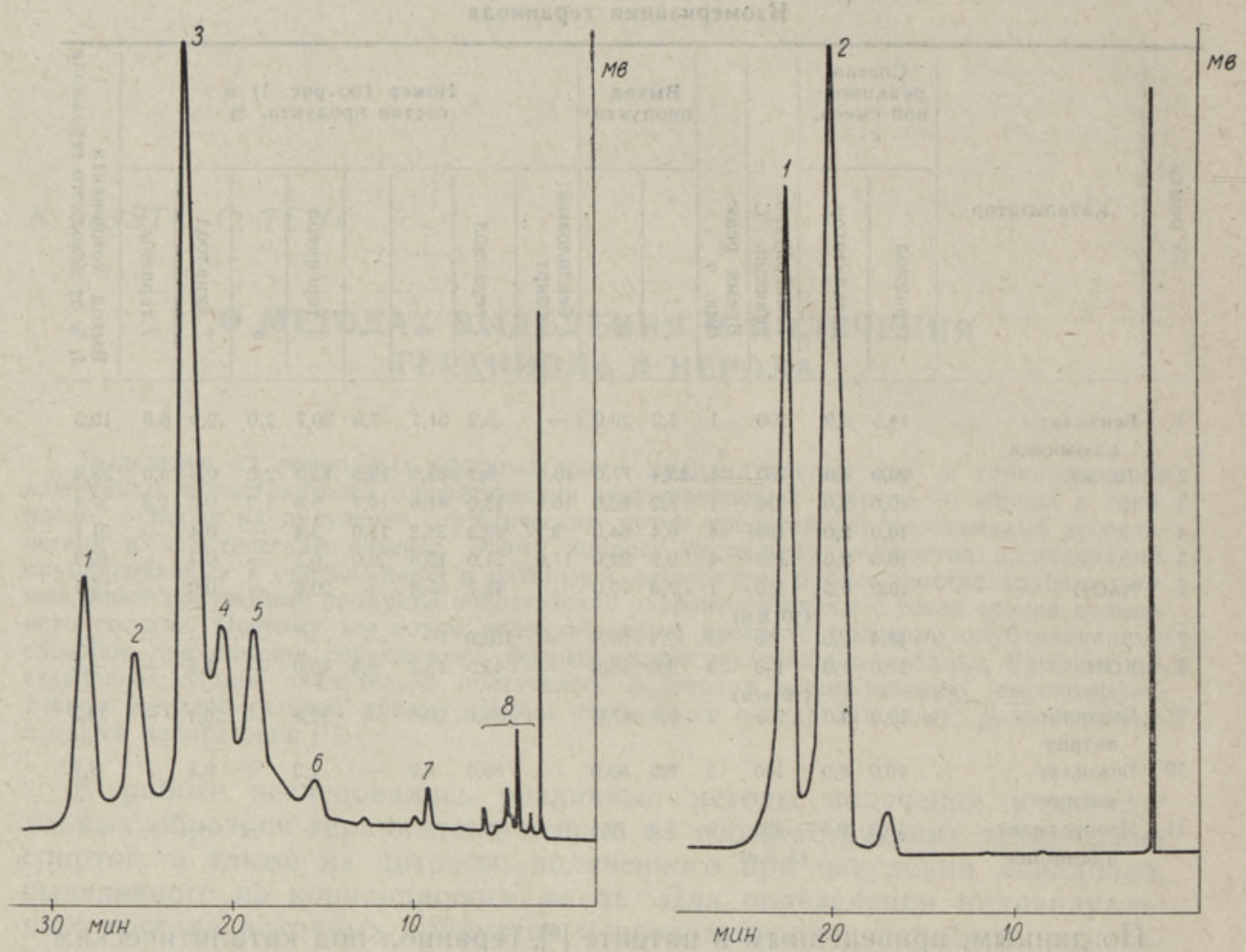

Рис. 1. Хроматограмма продукта изомеризации гераниола с бензилатом алюминия.

Рис. 2. Хроматограмма главного компонента изомеризации с неролом и гераниолом.

Особенного внимания заслуживал главный компонент 3 (см. табл. 1 и рис. 1) изомеризата. При разгонке изомеризата на колонке эффективностью 35-40 теоретических тарелок удалось выделить фракцию с содержанием 85-90\% компонента 3, которая подвергалась более подробному изучению. Для идентификации методом газовой хроматографии к пробе добавили смесь гераниола и нерола, полученную восстановлением цитраля. На хроматограмме (рис. 2) возрастает ширина пика 2 , соответствующего неролу. Это дало основание сомневаться в идентичности компонента 3 (рис. 1) с неролом, что было доказано в дальнейшем ходе исследования.

Кроме изученного метода, был подвергнут проверке опубликованный в 1919 г. [9] метод превращения гераниола в нерол в присутствии НJ, ссылки на который имеются и в последних обзорах $\left[{ }^{12,13}\right.$. Накопленные до настоящего времени данные о реакциях аллильных соединений [14] вызывают серьезные сомнения в возможности такого получения нерола. Это подтвердилось в наших экспериментах: при повторении получения йодида согласно прописи оригинала удалось получить продукт с содержанием около $34 \%$ первичных аллильных йодидов, который при гидролизе с метанольной щелочью дал гидролизат, состоящий 
главным образом (около 60\%) из метилового эфира гераниола (рис. 3 , пик 7). Методом эталонных веществ установили содержание в продукте еще гераниола - пик 1 , линалоола - пик 6 и терпинеола - пик 3 . Неролу на рис. 3 может соответствовать пик 2, что составляет ничтожную часть продукта.

Для препаративного получения нерола нами был проверен метод, разработанный Понндорфом в 1926 г. с применением изопропилата алюминия, позволяющий успешно восстанавливать природный цитраль в спирты [ $\left.{ }^{11}\right]$. По опубликованным данным реакция восстановления сопровождается изомеризацией в сторону образования нерола.

Новые данные об условиях данной реакции $\left.{ }^{15}\right]$ служили дополнительным материалом при изучении реакции восстановления цитраля и привели к разработке некоторых изменений в методике Понндорфа. Использованное Понндорфом количество изопропилата алюминия составляло $10 \%$ от веса цитраля, т. е. на 4,5 моля цитраля приходился 1 2-экв изопропилата алюминия. В данном исследовании опыты с увеличением количества изопропилата дали значительное сокращение времени реакции и увеличение выхода при соотношении $3: 1$ (15\% изопропилата алюминия от цитраля). Хотя и в этом количестве изопропилат действует как катализатор, можно добиться сокращения времени реакции в 4 раза и увеличения выхода на $12 \%$ (табл. 2, опыты 2 и 4). Выделение продукта реакции восстановления перегонкой в вакууме дало лучшие результаты, чем выделение перегонкой с водяным паром: увеличился выход продукта и содержание в нем нерола (табл. 2, опыты 1, 2). Составы цитраля и восстановленного продукта определяли при помощи газовой хроматографии. Исходный цитраль имел состав: $82,4 \%$ гераниаля и $17,6 \%$ нераля. В результате восстановления получили смесь с содержанием 45,4-$48,9 \%$ нерола и $54,6-51,1 \%$ гераниола (табл. 2). Для выделения нерола из продуктов восстановления метод, использованный Понндорфом, оказался непригодным, так как выделение гераниола в виде комплекса с хлористым кальцием не обеспечивает полного удаления его из смеси. Практически чистые (по данным газовой хроматографии) нерол и гераниол были нами по-

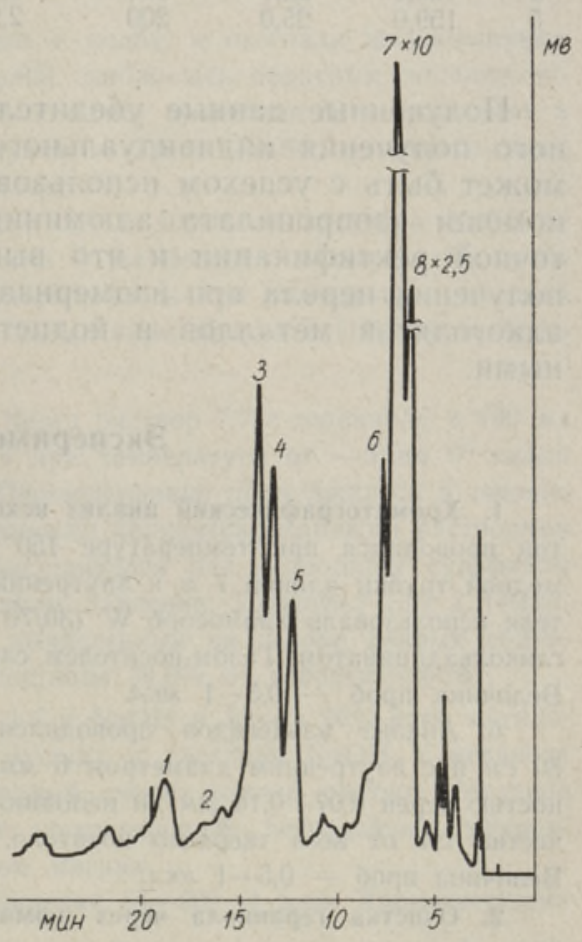

Рис. 3. Хроматограмма продукта изомеризацин гераниола с НJ. лучены ректификацией смеси в вакууме на колонке эффективностью 35-40 теоретических тарелок.

Для подтверждения достоверности наших выводов о получении нерола при восстановлении цитраля и о получении неидентичного с неролом спирта (см. рис. 1, компонент 3) при щелочной изомеризации гераниола оба вещества были превращены в хлорпроизводные при помощи $\mathrm{PCl}_{5}$. При попытке превращения хлоридов в цитраль по реакции Соммле в условиях, предложенных в работе [4], из хлорида, полученного из 
компоне́нта 3, альдегид не образовался. Хлорид, полученный из нерола, был преврашен в цитраль с хорошим выходом.

Таблица 2

Восстановление цитраяя

\begin{tabular}{|c|c|c|c|c|c|c|c|c|c|}
\hline \multirow[b]{2}{*}{ 일 } & \multicolumn{3}{|c|}{ Содержание, $е$} & \multirow{2}{*}{$\begin{array}{c}\text { Молярное } \\
\text { соотноше- } \\
\text { ние цитраль : } \\
\text { изопропи- } \\
\text { лат-Al }\end{array}$} & \multirow{2}{*}{$\begin{array}{l}\text { Методнка } \\
\text { выделения }\end{array}$} & \multicolumn{2}{|c|}{$\begin{array}{c}\text { Выход про- } \\
\text { дукта }\end{array}$} & \multicolumn{2}{|c|}{$\begin{array}{c}\text { Состав } \\
\text { продукта, \% }\end{array}$} \\
\hline & цнтраля & $\left|\begin{array}{c}\text { изопропи- } \\
\text { лат-Al }\end{array}\right|$ & \begin{tabular}{|c} 
нзопропи \\
лового \\
спирта
\end{tabular} & & & 2 & $\%$ & нерол & $\begin{array}{l}\text { гера- } \\
\text { ниол }\end{array}$ \\
\hline 1 & 5,0 & 0,5 & 10 & $4,5: 1$ & $\begin{array}{l}\text { Дистилля- } \\
\text { ция с водя- }\end{array}$ & 2,8 & 56,0 & 37,0 & 63,0 \\
\hline 2 & 50,0 & 5,0 & 70 & $4,5: 1$ & $\begin{array}{l}\text { Дистилля- } \\
\text { ция в ва- } \\
\text { кууме } \\
\text { (1 мм) }\end{array}$ & 31,0 & 62,0 & 48,9 & 51,1 \\
\hline $\begin{array}{l}3 \\
4 \\
5\end{array}$ & $\begin{array}{l}100,0 \\
165,0 \\
159,0\end{array}$ & $\begin{array}{l}13,4 \\
25,0 \\
25,0\end{array}$ & $\begin{array}{l}122 \\
200 \\
200\end{array}$ & $\begin{array}{l}3,3: 1 \\
3,0: 1 \\
2,9: 1\end{array}$ & $\begin{array}{l}\text { То же } \\
" \# " \\
\Rightarrow ",\end{array}$ & $\begin{array}{r}73,0 \\
122,0 \\
115,0\end{array}$ & $\begin{array}{l}73,6 \\
73,8 \\
72,2\end{array}$ & $\begin{array}{l}45,4 \\
42,6 \\
44,4\end{array}$ & $\begin{array}{l}54,6 \\
57,4 \\
55,6\end{array}$ \\
\hline
\end{tabular}

Полученные данные убедительно доказывают, что для препаративного получения индивидуального нерола из изученных нами методов может быть с успехом использован метод восстановления цитраля при помощи изопропилата алюминия с применением для его выделения точной ректификации и что выводы, сделанные ранее по вопросу о получении нерола при изомеризации гераниола в присутствии щелочей, алкоголятов металлов и йодистоводородной кислоты, являются ложными.

\section{Экспериментальная часть}

1. Хроматографический анализ исходных и получаемых веществ. а. Анализ спиртов проводился при температуре $150^{\circ} \mathrm{C}$ на хроматографе «Хром-1» с колонкой нз медной трубки длиной 7 м и внутренним диаметром 3 мм. В качестве твердого носителя использовали хромосорб W (30/70 меш Б. С.), пропитанный $4 \%$-ным полнэтиленгликольадипинатом. Газом-носителем служил $\mathrm{CO}_{2} ;$ скорость подачи газа $-20 \mathrm{M} /$ мин. Величнна проб - 0,5-1 мкл.

б. Анализ альдегидов проводился при температуре $100^{\circ}$ на колонке длиной $80 \mathrm{~cm}$ и с внутренним диаметром 6 мм. Твердым носителем служил целит 535 (крупностью зерен $0,07-0,16$ мм) и неподвижной фазой - полиэтиленгликоль 4000 в количестве $1 \%$ от веса твердого носителя. Скорость газа-носителя $\left(\mathrm{CO}_{2}\right)-35 \mathrm{M} / \mathrm{Muн}$. Величина проб - 0,5-1 мкл.

2. Очистка гераниола через комплексное соединение с хлористым кальцием. В колбу, снабженную мешалкой, хлоркальциевой трубкой и капельной воронкой, помещали 175 г безводного $\mathrm{CaCl}_{2}$ и 1000 мл петролейного эфира. Безводный $\mathrm{CaCl}_{2}$ получали прокаливанием при температуре $600-700^{\circ}$ и измельчением под высушенным петролейным эфиром.

При интенсивном перемешивании прибавляли 150 г технического гераннола (содержание гераниола по данным ГX $-42 \%$ ). Перемешивание продолжалось 2 ч. На следующий день отфильтрованный осадок промывали три раза петролейным эфиром (по 200 мл каждый раз) и разлагали прибавлением 1000 мл ледяной воды. Гераниол извлекали петролейным эфиром, промывали водой н после сушки над безводным $\mathrm{MgSO}_{4}$ перегоняли в вакууме. Получено 52,6 г гераннола при выходе $83,5 \%$ и следующих основных показателях: т. кип. $\quad 97,5-98,0^{\circ} \quad(5 \mathrm{M}) ; \quad d_{4}^{20}=0,8825 ; \quad n_{D^{20}}=1,4770$; MR 49,37, вычисленное MR 48,96. 
Данные литературы [16]: т. кип. $\quad 109-110^{\circ}(9 \quad$ мм $) ; \quad d_{4}{ }^{20}=0,8806 ; \quad n_{D}{ }^{20}=1,4760$, MR 49,39, вычисленное MR 48,96.

3. Изомеризация гераниола. а. В колбу с притертым обратным холодильником закладывали 14,5 г гераниола, очищенного через комплекс $\mathrm{c} \mathrm{CaCl}_{2}$, и 2,9 г бензилата алюминия [11]. Содержимое колбы нагревалось при температуре кипения 1 ч. Температура кипения реакционной смеси изменилась в конце реакции с 230 до $210^{\circ}$.

Полученные спирты выделялись перегонкой с водяным паром, высушивались над безводным сернокислым магнием и перегонялись в вакууме. Получено 4,2 г продукта (29,0\% от исходного гераниола), состав которого приведен в табл. 1 (опыт 1).

При выделении продукта изомеризации (10 г гераниола) перегонкой при давлении 4-5 м.м получено 8,2 г (82\%) вещества. Состав продукта приведен в табл. 1 (опыт 3) и на рис. 1.

б. В колбе, снабженной обратным холодильником, смесь 10 г гераниола и 2 ᄅ бензилата алюмнния нагревалась при $160^{\circ}$ в теченіе 4 ч.

Выделение продукта из реакционной смеси проводили при помощи перегонки с водяным паром (табл. 1, опыт 4) и перегонкой в вакууме 5-6 мм (табл. 1, опыт 5). Выходы изомеризата составили соответственно 64,0 и $92,0 \%$ от взятого гераниола. Составы продуктов приведены в табл. 1 .

в. 10 г гераниола и 0,5 г $\mathrm{NaOH}$ поместили в колбу, и отогнали выделившуюся в результате реакции воду при 25-30 м.м. Колба снабжалась обратным холодильником, и реакционная смесь выдерживалась при кипении в течении 1 ч (давление в системе 10 мм, темп. бани $\left.130^{\circ}\right)$. Выход продукта $-7,0$ г $(70,0 \%$ от взятого гераниола). Состав продукта приведен в табл. 1 (опыт 6).

г. K 18,4 г гераннола в колбе прибавляли 2,3 г $40 \%$-ного раствора $\mathrm{NaOH}$ в воде. Воду перегнали при 25-30 мм, прибавили 5 мл бензола; затем колба снабжалась обратным холодильником и смесь выдерживалась при температуре кипения бензола. По данным газовой хроматографии в выделенном продукте $(12,4$ г) не было других компонентов, кроме гераннола.

4. Получение и гидролиз геранилйодида. Через раствор 7,7 г гераниола в $100 \mathrm{M} \imath$ петролейного эфира пропускали в течение 1 ч при температуре от -5 до $0^{\circ}$ около 0,05 моля газообразного йодистого водорода. Перемешиванне продолжалось в теченне 2 ч. Продукт реакции промывался охлажденными концентрированными растворами бикарбоната натрия и хлорнстого кальция, высушнвался над безводным сульфатом магння и растворнтель отгонялся прн пониженном давлении. Получено 13,7 г темнокорнчневого продукта. Выход гераннлйоднда, вычисленный на основе данных содержания первичного йода в продукте $(16,0 \%)$, составил $34,6 \%$ от теоретического.

Гндролиз продукта провели кнпячением с 1,5 г $\mathrm{NaOH}$ в 50 мл 90\%-ного метилового спирта. Несмешивавшнеся сначала слон йодида и раствора $\mathrm{NaOH}$ в метаноле после 4-часового кипячения перешли в однородный светло-желтый раствор. Метанол отгоняли при пониженном давленин, продукт экстрагировали петролейным эфиром, промывали водой и высушивали над сульфатом магния.

Получено 1,8 г продукта с температурой кнпения $55-80^{\circ}$ (1 мм). Хроматограмма продукта показана на рнс. 3.

5. Восстановление цитраля. а. В 0,5-литровую круглодонную колбу помещалось 165 г свежеперегнанного цнтраля, 25 г перегнанного изопропнлата алюмнния, приготовленного из амальгамированного алюминия и нзопропилового спирта [1 ${ }^{0}$, и 200 г абсолютного изопропилового спирта. Колбу соеднннли с ректнфикацнонной колонкой, и содержимое нагревалось до $90-95^{\circ}$ с медленной перегонкой ацетона. Нагревание вели до прекращення выделения ацетона $(10-15$ ч). Полноту восстановления определяли с помощью качественной пробы в дистиллате на ацетон с 2,4-динитрофенилгнд. разнном. После окончання восстановления из реакционного продукта отгоняли изогропиловый спирт и продукт реакции перегонялн при $1-2$ мм.

Получено 122,9 г продукта с температурой кипения $80-86^{\circ}$. Состав продукта по данным газовой хроматографии: $42,6 \%$ нерола и $57,4 \%$ гераниола. 
б. 253 г продукта восстановления, состоящего из $47,5 \%$ нерола и $52,5 \%$ гераниола подвергали ректификации на колонке эффективностью 35-40 теоретических тарелок Получено 93,0 г гераниола и 59,5 г чистого нерола со следующими основными показателями: т. кип. $94,0^{\circ}(5 \mathrm{M \mu}) ; n_{D}{ }^{20}=1,4760 ; d_{4}{ }^{20}=0,8788 ; \quad \mathrm{MR} 49,49, \mathrm{MR}$ вычисленное 48,96 .

Данные литературы для нерола: $d_{4}{ }^{20}=0,8756 ; n_{D}{ }^{20}=1,4746 ; \quad$ MR $49,53\left[{ }^{17}\right] ; \quad$. кип. $103-105^{\circ}(9 \mathrm{M \mu}) ; \quad d_{4^{20}}=0,8762 ; n_{D}{ }^{20}=1,4744 ;$ т. пл. дифенилуретана $50,5-51^{\circ}\left[{ }^{16}\right]$,

6. Превращение спиртов в альдегиды при помощи реакции Соммле. а. К 10 己 хорошо измельченного $\mathrm{PCl}_{5}$ в $150 \mu \Omega$ петролейного эфира прибавляли в течение 1,5 ч при температуре от $-10^{\circ}$ до $-12^{\circ} 7,2$ г нерола. Перемешивание продолжалось 1,5 ч. Продукт реакции промывали охлажденными концентрированными растворами карбюната натрия и хлористого кальция и высушивали над безводным хлористым кальцием. После отгонки большинства растворителя под пониженным давлением получено 11,5 г продукта. Содержание в продукте хлорида, вычисленное на основании данных определения содержания первичного аллильного хлора $-8,7 \%\left[{ }^{3}\right]$, составляло $60,0 \%$ от теоретического.

б. Из 2,8 г синтезированного хлорида, 0,5 г уротропина и 4 г формалина получнли методом Соммле (см. [4]) 0,2 г альдегида, который по данным газовой хроматографин представлял собой цитраль-б с небольшой примесью цитраля-а.

в. Из 8,0 г фракций спиртов (опыт 3а) с содержанием 90,6\% компонента 3 в условиях опыта 6 а получен продукт, содержащий $54,5 \%$ хлоридов.

Соответствующего альдегида из 7,0 г полученного хлорида в условиях опыта 66 получить не удалось.

\section{Выводы}

1. Изучен ряд известных методов выделения и получения гераниола и нерола с использованием газохроматографических методов анализа для определения состава продуктов.

2. Установлено, что гераниол достаточной чистоты может быть выделен из технических смесей через соединение $\mathrm{c} \mathrm{CaCl}_{2}$, а также точной вакуумной ректификацией. Для очистки нерола последний метод недостаточно эффективен.

3. Изучены реакции изомеризации гераниола в нерол в присутствии щелочей, алкоголятов металлов и йодистоводородной кислоты. Установлено, что в условиях данных реакций нерол не образуется, а получается сложная смесь продуктов изомеризации.

4. Изучена реакция восстановления цитраля при помощи изопропилата алюминия. Установлено, что цитраль восстанавливается в условиях данной реакции в смесь гераниола и нерола с преимущественным образованием нерола. Найдено, что индивидуальные спирты могут быть выделены из продукта реакции с хорошим выходом при помощи вакуумной ректификации.

\section{ЛИТЕ РАТ У Р А}

1. Л ээтс К., Эрм А., Изв. АН ЭССР. Сер. физ.-матем. и техн. наук, 13, № 1, 57 (1964).

2. Ruzick a L., Helv. Chim. Acta, 6, 492 (1923).

3. Л ээ тс К. В. и др., ЖОХ, 27, 2969 (1957).

4. Л э э т с К. В. и др., ЖОХ, 27, 1510 (1957).

5. Bedoukian P. Z., Perfumery Synthetics and Isolates, New-York-TorontoLondon, 1956, p. 212.

6. Söhne A. D., P o n nd or f W., Германский патент 462895.

7. Isao O gur a, Yapan 8107 [Chem. Abstrs, 59, 11573d]. 
8. Kimiko Nagai, Nippon Kagaku Zasshi, 82, 613 (1961) [Chem. Abstrs, 57, $13807 \mathrm{c}]$.

9. Verley A., Bull. [4], 25, 68 (1919).

10. Z e it s che l, Ber., 39, 1786 (1906).

11. P o n nd orf W., Z. Angew. Chem., 39, 138 (1926).

12. Ис агульянц В. И., Синтетические душистые вещества, Ереван, 1946, с. 141.

13. Simonsen J. L., The Terpenes, vol. 1, Cambridge, 1947, p. 40.

14. De Wolf e R. H., Y oung W. G., Chem. Rews, 56, 753 (1956).

15. Органические реакции, сб. 2, М., 1950, с. 194.

16. Н а з а ров И. Н. и др., ЖОХ, 28, 1444 (1958).

17. N a ves Y. R., A r d i z i o P., Compt. rend., 234, 2433 (1952).

Ннститут химии

Академии наук Эстонской ССР

Поступила в редакцию 22/II 1967

\section{K. LÄATS, S. TENG}

\section{GERANIOOLI JA NEROOLI ERALDAMIS- JA SAAMISMEETODITE UURIMINE}

Gaasikromatograafiliselt uuriti geraniooli ja nerooli eraldamis- ning saamismeetodeid eesmärgiga töötada välja sobivad meetodid puhaste geraniooli ja nerooli saamiseks suuremates hulkades.

Geraniooli eraldati suhteliselt lihtsalt kas rektifikatsiooniga või kaltsiumkloriidiga moodustuva tahke kompleksi kaudu.

Looduslikes eeterlikes ölides sisalduvate väikeste neroolihulkade eraldamine ja enamik kirjanduses avaldatud meetodeid ei oma nerooli saamise seisukohalt praktilist tähtsust. Uuriti lähemalt geraniooli isomerisatsiooni leeliseliste katalüsaatorite ja joodvesinikhappe toimel, kuid isomerisatsiooniproduktides leiduv tähtsusetu hulk nerooli ei võimaldanud ka neid meetodeid kasutada. Sobivaks nerooli saamise meetodiks osutus ainult tsitraali taandamisel alumiiniumisopropülaadiga saadava geraniooli ja nerooli segu rektifikatsioon.

\section{K. LÄATS, S. TENG}

\section{EXPERIMENTS RELATING TO THE SEPARATION AND PREPARATION OF GERANIOL AND NEROL}

The known methods of separation and purification of geraniol and nerol were studied by gas chromatography in order to establish a method for the production of preparative amounts of pure geraniol and nerol.

The separation of comparatively pure samples of geraniol was a relatively easy matter. One procedure consisted of careful fractional distillation of the oil through an efficient fractionating column. Another method depended upon chemical separation by a crystalline derivative with calcium chloride.

The separation of nerol was not a practical matter because most of the essential natural oils contained very small quantities of nerol. Most of the reported methods for the preparation of nerol have little practical value. A thorough study was made of the conversion of geraniol into nerol by the action of the inorganic bases or alcoholates at elevated temperatures as well as by Verley's method when geraniol was treated with hydrogen iodide and alkali. In both isomeric reaction products no appreciable amount of nerol was discovered. Pure nerol was prepared by the reduction. of citral with aluminium isopropylate. Optimal reaction conditions were elaborated. 